\title{
Accelerated Atherosclerosis in a Young Female with Familial Hypercholesterolemia
}

\author{
Adikesava Naidu Otikunta1, Praneeth Polamuri1 ${ }^{1}$, Subba Reddy Y V1, Ravi Srinivas', \\ Ashok Thakkar', Arohi Sarang2 \\ ${ }^{1}$ Department of Cardiology, Osmania General Hospital \& Osmania Medical College, Hyderabad, India \\ ${ }^{2}$ Department of Clinical Trials, Sahajanand Medical Technologies Pvt. Ltd., Surat, India \\ Email: oadikesavanaidu@gmail.com
}

Received 28 March 2014; revised 26 April 2014; accepted 2 May 2014

Copyright (C) 2014 by authors and Scientific Research Publishing Inc.

This work is licensed under the Creative Commons Attribution International License (CC BY). http://creativecommons.org/licenses/by/4.0/

(c) (i) Open Access

\begin{abstract}
Familial hypercholesterolemia is an autosomal dominant genetic disease due to mutation in lowdensity lipoprotein-cholesterol receptor gene. It is characterized by elevated plasma low-density lipoprotein-cholesterol and the consequence of which leads to premature cardiovascular disease. The mainstay in the management of familial hypercholesterolemia patient is the treatment with high potency statin. However, current research shows influence of the type of low-density lipoprotein-cholesterol receptor mutations on severity of the cardiovascular disease, lipid profile, and response to statin treatment. We are here presenting a case of young Indian female patient who was diagnosed with familial hypercholesterolemia and treated with percutaneous trans-luminal coronary angioplasty in view of double vessel disease in the third decade of her life. She was prescribed with statin therapy for elevated low-density lipoprotein cholesterol. After 3 years, she presented once again with a triple vessel disease along with patent stented segments and abnormal lipid profile.
\end{abstract}

\section{Keywords}

Familial Hypercholesterolemia, Premature Coronary Artery Disease, Statin

\section{Introduction}

Heterozygous familial hypercholesterolemia (FH) is an autosomal dominant genetic disease. Due to the mutation in low-density lipoprotein-cholesterol receptor (LDLR), the disease is characterized by elevated level of plasma low-density lipoprotein-cholesterol (LDL-C) and thereby increases the incidence of premature cardiovascular disease (PCVD) in the affected individuals in the early decades of their lives [1]. The occurrence of 
the PCVD can be prevented by providing adequate treatments but it has been found that only $5 \%$ of the individuals, affected by FH, are treated adequately [2] [3]. In addition, current research ascertains that the lipid profile as well as response of patient to statin treatment depends upon the type of LDLR gene mutation [4]-[6].

We are here presenting a case of young female who was clinically diagnosed with FH in the third decade of her life. Even though the patient was aggressively treated with life style modification and with pharmacological therapy, her lipid profile remained abnormal and she experienced cardiovascular disease repeatedly. This casereport highlights the need to determine the influence of LDLR gene mutation in response to statin therapy. So, the patient can be treated adequately to prevent PCVD based upon the knowledge of type of gene mutation.

\section{Case Report}

A 30 years old female attended the clinic for a regular check-up. She was of normal built, having BMI of 28.8 $\mathrm{kg} / \mathrm{m}^{2}$. She was normotensive and non-diabetic. She complained about the multiple yellowish plaques over knees, ankles and buttocks.

Upon examinations, we found tendon xanthoma over knees, ankles and buttocks along with xanthelasma on eyelids and corneal arcus. Her laboratory investigations also revealed abnormal lipid profile (Table 1).

Her family history was suggestive of abnormal lipid profile in the early decades of life (Table 2) as well as tendon xanthomas in her three siblings. She denied having coronary artery disease (CAD) or pre-mature death of family member due to CAD.

Other laboratory examinations, i.e. thyroid function tests (T3, T4 and TSH), liver function tests (AST, ALT, $\gamma$-GGT) and renal function tests (serum creatinine, urinalysis) were normal. We clinically diagnosed the patient with FH. The genetic analysis would conclude if she is having homogeneous FH or heterogeneous FH. A systemic examination (electrocardiogram [ECG], two-dimensional echocardiogram, treadmill test) of the cardiovascular system revealed normal findings. The patient was prescribed ATOCOR-E (atorvastatin $10 \mathrm{mg}+$ ezetimibe $10 \mathrm{mg}$ ) along with life style modifications.

Table 1. Lipid profile of the patient at the time of diagnosis, follow-up and at the time of presentations of coronary artery disease.

\begin{tabular}{|c|c|c|c|c|c|}
\hline Parameters & $\begin{array}{l}\text { Normal laboratory } \\
\text { values }\end{array}$ & $\begin{array}{l}\text { At the time of } \\
\text { initial diagnosis }\end{array}$ & $\begin{array}{l}\text { At the time of 1st time } \\
\text { presentation of CAD }\end{array}$ & $\begin{array}{l}\text { During } \\
\text { follow-up }\end{array}$ & $\begin{array}{l}\text { At the time of 2nd time } \\
\text { presentation of CAD }\end{array}$ \\
\hline Total Cholesterol (mg/dL) & $<200$ & 462 & 463 & 390 & 444 \\
\hline Triglycerides (mg/dL) & $<150$ & 70 & 62 & 79 & 100 \\
\hline $\begin{array}{l}\text { Low-density lipoprotein-cholesterol } \\
\text { (mg/dL) }\end{array}$ & $<100$ & 287 & 293 & 255 & 384 \\
\hline $\begin{array}{l}\text { High-density lipoprotein-cholesterol } \\
\text { (mg/dL) }\end{array}$ & $>60$ & NA & 56 & 47 & 40 \\
\hline Apolipoprotein (mg/dL) & $<30$ & NA & NA & NA & 22.9 \\
\hline
\end{tabular}

Table 2. Lipid profile of the siblings of the patient.

\begin{tabular}{cccccc}
\hline & \multicolumn{5}{c}{ Lipid profile of the siblings } \\
\cline { 2 - 6 } Parameters & 40 years/female & 30 years/Male & 28 years/Male & 25 years/Male & 23 years/Male \\
\hline Total Cholesterol (mg/dL) & 207 & 190 & 269 & 351 & 313 \\
Triglycerides (mg/dL) & 97 & 87 & 109 & 118 & 119 \\
Low-density lipoprotein-cholesterol (mg/dL) & 146 & 133 & 204 & 286 & 241 \\
Very low-density lipoprotein-cholesterol (mg/dL) & 19 & 17 & 21 & 23 & 23 \\
High-density lipoprotein-cholesterol (mg/dL) & 42 & 40 & 44 & 42 & 49 \\
Xanthoma & No & No & Present & Present & Present \\
\hline
\end{tabular}


After 2 months of the diagnosis, she presented to the clinic with the complaints of chest pain. ECG was suggestive of acute anterior wall ST elevation myocardial infarction (MI) which was thrombolysed with streptokinase. She underwent coronary angiography which revealed double vessel disease (DVD) (Figure 1(A)) for which she underwent percutaneous transluminal coronary angioplasty (PTCA) with $3 \times 16 \mathrm{~mm}$ stent placement to mid segment of left anterior descending artery (LAD) and $3 \times 10 \mathrm{~mm}$ stent in second obtuse marginal (OM) branch of left circumflex artery (LCX) (Figure 1(B)). She was discharged on ROSUVAS (rosuvastatin $20 \mathrm{mg}$ ), antiplatelets (aspirin/clopidogrel 150/150 mg for 1 year followed by aspirin/clopidogrel 150/75 mg), Starpress XL (metoprolol $50 \mathrm{mg}$ twice daily) and Cardace (ramipril $5 \mathrm{mg}$ ). There was no complication observed during follow-up period but the lipid profile was still remained abnormal.

After 3 years of PTCA, the patient again came to the clinic with same complaints of rest angina since 2 days, not responding to sublingual nitrates. She also had shortness of breath (NYHA class II). She denied having any history of palpitations, syncope or easy fatigability. Her fasting lipid profile is shown in Table 1. Hematogram and other biochemical investigations were within normal range. ECG showed non-specific ST and T changes while cardiac biomarkers were not elevated. Echocardiogram showed good biventricular function with no gross abnormality. After initial medical therapy, she underwent coronary angiogram which showed triple vessel disease (TVD), diffuse narrowing of the proximal and mid segments of right coronary artery with 100\% occlusion in distal segment, diffuse narrowing with $90 \%$ stenosis in the proximal segment of LCX showed and diffuse narrowing with $60 \%$ stenosis in the proximal segment of LAD (Figure 1(C) \& Figure 1(D)). However the previously stented segments were patent with TIMI-III flow. In view of unfavorable anatomy, she was referred to surgeon for coronary artery bypass grafting.

\section{Discussion}

Here, in this case-report we have described a case of young female patient who had been diagnosed with FH based upon Dutch lipid clinic network criteria [3], i.e. elevated level of LDL-C (287 mg/dL), presence of tendon xanthoma, xanthelasma and corneal arcus, first degree relative with raised LDL-C along with xanthoma. We had

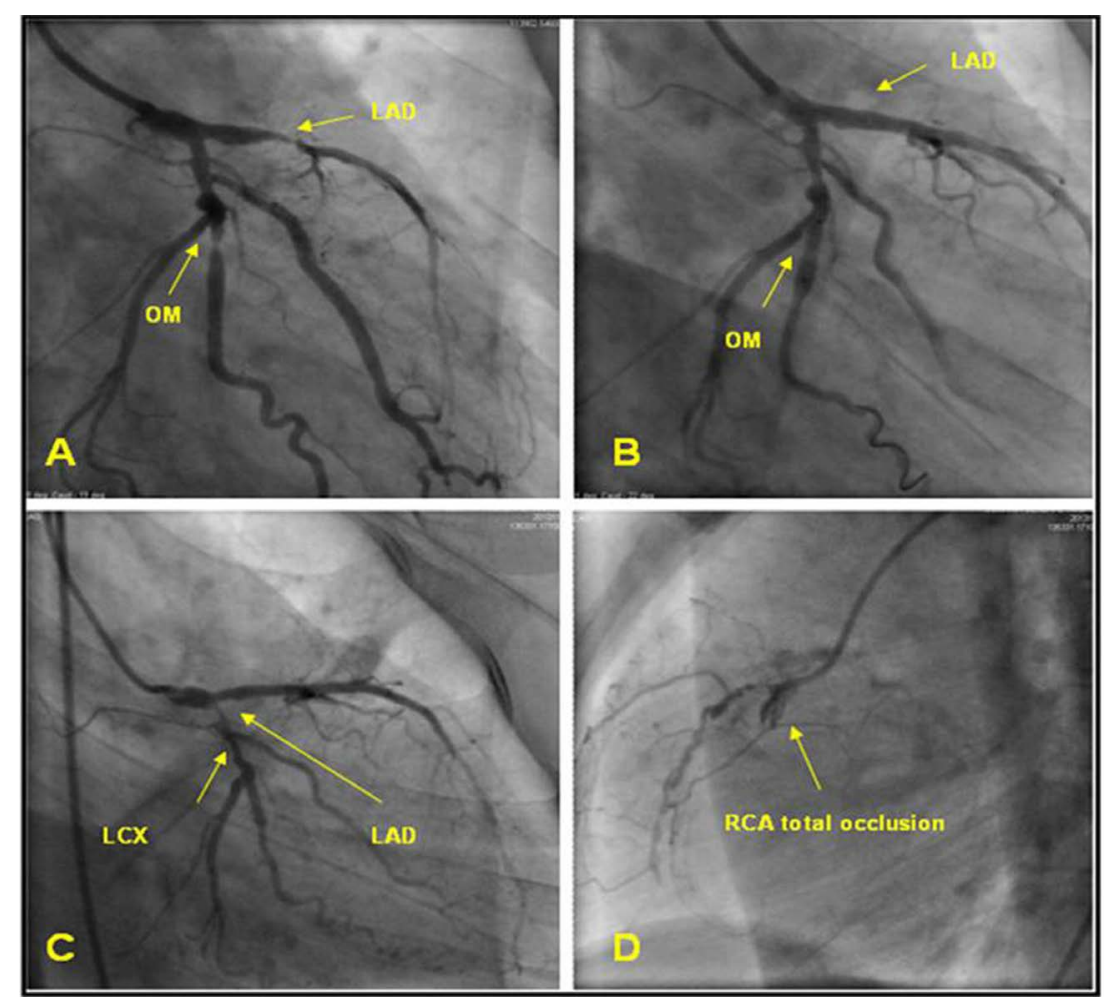

Figure 1. (A) First coronary angiography revealed double vessel disease; (B) PostPCI of double vessel disease; (C) \& (D) Coronary angiograph demonstrated triple vessel disease after three years of first PCI. 
ruled out other possible clinical conditions (thyroid dysfunction, nephrotic syndrome, medications) that may lead to hypercholesterolemia. The patient was clinically (based on phenotype) diagnosed with FH. The cardiovascular system was found normal. As the patient was at high risk of development of coronary heart disease, we advised the patients to modify life-style along with pharmacological treatment-atorvastatin and ezetimibe. However, she developed DVD after 3 months of diagnosis for which PTCA was carried out. As the lipid profile was not achieved by the combination therapy of atorvastatin and ezetimibe, we prescribed rosuvastatin to the patient along with pharmacological treatment (metoprolol and ramipril) to prevent remodelling and arryhthmias in view of post-MI with left ventricular dysfunction. Even though the patient was prescribed high-dose statin therapy, she developed TVD after three years of PTCA. It is noteworthy that lipoprotein level was found normal in our patient.

The influence of the type of LDL-receptor mutations on lipid profile, severity of coronary artery disease and on response to treatment is not completely clear, and few studies have been performed with controversial findings. Our case-report strengthens the finding that the type of mutations of LDLR influences severity of coronary artery disease, lipid profile and response statin treatment.

Based on phenotypic effects, five classes of LDL-receptor mutations have been proposed. Class-I mutations are non-allele mutations. Due to large deletions and promoter mutations (Class-I mutations), there is no detectable LDL receptor protein. Class-II mutations (transport defective alleles) cause either complete (Class-II a) or partial (Class-II b) block of the transport of the LDL receptor from the endoplasmic reticulum to the Golgi apparatus. Defective LDL binding results in Class-III mutations and Class-IV mutations cause a deficiency in the internalization of LDL and Class-V mutations fail to recycle effectively.

Alonso et al. in their large cross-sectional studies found that the patients carrying null-mutations had significantly higher frequency of PCVD (1.7 folds higher) and recurrence of cardiovascular events [7]. Similar observations were also seen in other studies [8] [9]. The mutations of LDLR gene also affect severity of cardiovascular disease [7] [10] [11]. Junyent et al. had carried out a study to determine the effects of different mutations in LDLR gene and coronary heart disease by considering carotid intima-media thickness and they found that null-allele mutations of LDLR gene show more severe clinical phenotype independent of age, gender, lipid and non-lipid risk factors and cholesterol-year scores [5]. In addition to severity of coronary heart disease, it has been found out that the patients with receptor-negative (null-allele) mutations of LDLR gene show more severe lipid phenotype than those with receptor-defective mutations [11]-[13]. However, the studies show controversial results for the association between type of LDLR gene mutations and response to statin treatment. Sun et al. has observed no association between response to simvastatin treatment and LDL-receptor defects in 42 patients diagnosed with heterozygous FH [14]. Similar conclusion was observed in the study carried out by Sijbrands et al. [15]. On the other hand, Chaves et al. observed poor responses to statin treatment in patients with null-allele mutations when compared to the response of defective mutations [16]. Miltiadous et al. also indicated class V mutations exhibit better response as compared to class-II mutations in 49 patients [6].

In our case, due to cost consideration we could not carry out genetic analysis to confirm the type of mutation. However, this case highlights the need of research in this area so that the patient can be adequately treated and thereby PCVD can be prevented or delayed.

\section{References}

[1] Nordestgaard, B.G., Chapman, M.J., Humphries, S.E., Ginsberg, H.N., Masana, L., et al. (2013) Familial Hypercholesterolaemia Is Underdiagnosed and Undertreated in the General Population: Guidance for Clinicians to Prevent Coronary Heart Disease Consensus Statement of the European Atherosclerosis Society. European Heart Journal, 34, 3478-3490. http://dx.doi.org/10.1093/eurheartj/eht273

[2] Marks, D., Thorogood, M., Neil, H.A. and Humphries, S.E. (2003) A Review on the Diagnosis, Natural History, and Treatment of Familial Hypercholesterolaemia. Atherosclerosis, 168, 1-14. http://dx.doi.org/10.1016/S0021-9150(02)00330-1

[3] Familial Hypercholesterolaemia (FH): Report of a Second WHO Consultation, Geneva, 4 September 1998. World Health Organization, Human Genetics Program, 1999.

[4] Karayan, L., Qiu, S., Betard, C., Dufour, R., Roederer, G., et al. (1994) Response to HMG CoA Reductase Inhibitors in Heterozygous Familial Hypercholesterolemia Due to the 10-kb Deletion ("French Canadian Mutation") of the LDL Receptor Gene. Arteriosclerosis, Thrombosis, and Vascular Biology, 14, 1258-1263.

http://dx.doi.org/10.1161/01.ATV.14.8.1258 
[5] Junyent, M., Gilabert, R., Jarauta, E., Núñez, I., Cofán, M., et al. (2010) Impact of Low-Density Lipoprotein Receptor Mutational Class on Carotid Atherosclerosis in Patients with Familial Hypercholesterolemia. Atherosclerosis, 208, 437-441. http://dx.doi.org/10.1016/j.atherosclerosis.2009.07.058

[6] Miltiadous, G., Xenophontos, S., Bairaktari, E., Ganotakis, M., Cariolou, M., et al. (2005) Genetic and Environmental Factors Affecting the Response to Statin Therapy in Patients with Molecularly Defined Familial Hypercholesterolaemia. Pharmacogenetics and Genomics, 15, 219-225. http://dx.doi.org/10.1097/01213011-200504000-00005

[7] Alonso, R., Mata, N., Castillo, S., Fuentes, F., Saenz, P., et al. (2008) Cardiovascular Disease in Familial Hypercholesterolaemia: Influence of Low-Density Lipoprotein Receptor Mutation Type and Classic Risk Factors. Atherosclerosis, 200, 315-321. http://dx.doi.org/10.1016/j.atherosclerosis.2007.12.024

[8] Bertolini, S., Cantafora, A., Averna, M., Cortese, C., Motti, C., et al. (2000) Clinical Expression of Familial Hypercholesterolemia in Clusters of Mutations of the LDL Receptor Gene that Cause a Receptor-Defective or Receptor-Negative Phenotype. Arteriosclerosis, Thrombosis, and Vascular Biology, 20, E41-E52. http://dx.doi.org/10.1161/01.ATV.20.9.e41

[9] Koeijvoets, K.C., Rodenburg, J., Hutten, B.A., Wiegman, A., Kastelein, J.J., et al. (2005) Low-Density Lipoprotein Receptor Genotype and Response to Pravastatin in Children with Familial Hypercholesterolemia: Substudy of an Intima-Media Thickness Trial. Circulation, 112, 3168-3173. http://dx.doi.org/10.1161/CIRCULATIONAHA.105.565507

[10] Jansen, A.C., van Wissen, S., Defesche, J.C. and Kastelein, J.J. (2002) Phenotypic Variability in Familial Hypercholesterolaemia: An Update. Current Opinion in Lipidology, 13, 165-171. http://dx.doi.org/10.1097/00041433-200204000-00008

[11] Austin, M.A., Hutter, C.M., Zimmern, R.L. and Humphries, S.E. (2004) Familial Hypercholesterolemia and Coronary Heart Disease: A HuGE Association Review. American Journal of Epidemiology, 160, 421-429. http://dx.doi.org/10.1093/aje/kwh237

[12] Koeijvoets, K.C., Wiegman, A., Rodenburg, J., Defesche, J.C., Kastelein, J.J., et al. (2005) Effect of Low-Density Lipoprotein Receptor Mutation on Lipoproteins and Cardiovascular Disease Risk: A Parent-Offspring Study. Atherosclerosis, 180, 93-99. http://dx.doi.org/10.1016/j.atherosclerosis.2004.10.042

[13] Humphries, S.E., Whittall, R.A., Hubbart, C.S., Maplebeck, S., Cooper, J.A., et al. (2006) Genetic Causes of Familial Hypercholesterolaemia in Patients in the UK: Relation to Plasma Lipid Levels and Coronary Heart Disease Risk. Journal of Medical Genetics, 43, 943-949. http://dx.doi.org/10.1136/jmg.2006.038356

[14] Sun, X.M., Patel, D.D., Knight, B.L. and Soutar, A.K. (1998) Influence of Genotype at the Low Density Lipoprotein (LDL) Receptor Gene Locus on the Clinical Phenotype and Response to Lipid-Lowering Drug Therapy in Heterozygous Familial Hypercholesterolaemia. The Familial Hypercholesterolaemia Regression Study Group. Atherosclerosis, 136, 175-185. http://dx.doi.org/10.1016/S0021-9150(97)00181-0

[15] Sijbrands, E.J., Lombardi, M.P., Westendorp, R.G., Leuven, J.A., Meinders, A.E., et al. (1998) Similar Response to Simvastatin in Patients Heterozygous for Familial Hypercholesterolemia with mRNA Negative and mRNA Positive Mutations. Atherosclerosis, 136, 247-254. http://dx.doi.org/10.1016/S0021-9150(97)00216-5

[16] Chaves, F.J., Real, J.T., Garcia-Garcia, A.B., Civera, M., Armengod, M.E., et al. (2001) Genetic Diagnosis of Familial Hypercholesterolemia in a South European Outbreed Population: Influence of Low-Density Lipoprotein (LDL) Receptor Gene Mutations on Treatment Response to Simvastatin in Total, LDL, and High-Density Lipoprotein Cholesterol. The Journal of Clinical Endocrinology \& Metabolism, 86, 4926-4932. http://dx.doi.org/10.1210/jcem.86.10.7899 